\title{
Effect of Aspidiotus rigidus infestation on the volatile chemical profile of the host plant Garcinia mangostana
}

\author{
M.A.A. Tavera',2, J.C.A. Lago3, V.K.D. Magalong3, G.A.V. Vidamo3, \\ J.S.R. Carandang VI',3, D.M. Amalin ${ }^{1,3}$ and J.I.B. Janairo ${ }^{1,3 *}$
}

Summary Plants respond to stress or damage by releasing volatile compounds, primarily for defense purposes. These volatiles function as signals for different interactions of the plant with its environment. In this study, the volatile chemical profile of healthy Garcinia mangostana L. (mangosteen) leaves was compared against leaves infested with the scale insect, Aspidiotus rigidus Reyne (Hemiptera: Diaspididae) through solid phase microextraction (SPME) coupled with gas chromatography- mass spectrometry (GC-MS). Analyses revealed that leaves emit the terpene kaur-16-ene in response to A. rigidus infestation. Kaur-16-ene is a precursor of gibberellin, a plant hormone for growth and development. The results suggest that the emission of kaur-16-ene in infested $G$. mangostana may play a role relevant in increasing the resistance of the plant towards infestations by herbivores.

Additional keywords: diterpenes, plant physiology, scale insect, semiochemistry

\section{Introduction}

Plants adopt various mechanisms to deter and counteract herbivore - induced damage. The emission of volatile chemicals upon attack is one of the effective ways plants deal with herbivory. These herbivore - induced plant volatiles (HIPV) serve various purposes such as a warning to surrounding plants of similar species, attract predators of the herbivore (De Moraes et al.,1998), and increase the fitness and vitality of the HIPV emitting plant (Schuman et al., 2012). The identification of HIPVs is not only important for understanding complex plant - insect dynamic interactions, but it can also pave the way for the development of effective and sustainable pest control measures (Shrivastava et al., 2010; Dicke et al., 1990). Regarding the

\footnotetext{
1 Biological Control Research Unit, Center for Natural Sciences and Environmental Research, De La Salle University, 2401 Taft Avenue, Manila 0922, Philippines

2 Chemistry Department, College of Science, De La Salle University, 2401 Taft Avenue, Manila 0922, Philippines

${ }^{3}$ Biology Department, College of Science, De La Salle University, 2401 Taft Avenue, Manila 0922, Philippines

* Corresponding author: jose.isagani.janairo@dlsu. edu.ph
}

chemical profile of HIPVs, the green leaf volatiles (GLV) which are released by the plants as soon as they are attacked or wounded, are composed mainly of alcohols, aldehydes, and esters. In addition, the volatile signals that are commonly released for defense include secondary metabolites produced from different pathways like lipoxygenase (LOX), shikimic acid, and terpenoids (Dudareva et al., 2006).

Recently, a massive infestation on plantations of coconut, Cocos nucifera (L.) (Arecaceae), was observed in the Philippines by the coconut scale insect, Aspidiotus rigidus Reyne (Hemiptera: Diaspididae). The infestation caused a great decline in the coconut palms of the area, affecting around 50-70\% of the coconut farms in 2013 (Watson et al., 2015). Another economically important host of the scale is mangosteen, Garcinia mangostana L. (Clusiaceae). It is considered a priority crop in the Philippines wherein 13,352 metric tons of this fruit was produced during the 2007 - 2011 period (Bureau of Agricultural Statistics, 2012).

Aspidiotus rigidus settles on the lower surface of the leaf, blocking the stomata and preventing the plant to photosynthesize which may even result to death (Watson et al., 2015). Little is known about the inter- 
action of $A$. rigidus with the host plant and information about scale insect - induced volatile compounds is scarce. Considering that scale insects in general pose a serious threat to agricultural productivity (Miller et al., 2005), understanding their interaction with the host plant is of paramount importance. In this study, the effect of $A$. rigidus infestation on the volatile chemical profile of the host plant G. mangostana was investigated. Aspidiotus rigidus is the only scale species infesting mangosteen (Watson et al., 2015) and hence its selection as host plant in the experiments eliminates the possibility for infestation of the plant tissue by other similar scale insect species, e.g. Aspidiotus desctructor Signoret (Hemiptera: Diaspididae), infesting coconut. The results presented are expected to contribute to the understanding of the pest - host plant interaction, which may be useful in devising strategies to mitigate the damage caused by $A$. rigidus.

\section{Materials and Methods}

\section{Leaf Sample Collection}

Healthy and A. rigidus - infested mangosteen leaves were collected from De La Salle University - Science and Technology Complex in Laguna, Philippines from January to May 2016. Mature leaves weighing $1.5 \mathrm{~g}$ to $4.5 \mathrm{~g}$ were used for the analysis. For the infested leaves, leaves with similar degrees of infestation were harvested on the basis of visual estimation of the presence of scales on the underside of the leaves (number of scales). The collected leaves were acclimatized for 1 hour prior to analysis.

\section{Extraction of Volatiles}

To extract the volatiles, a Supelco $0.1 \mathrm{~mm}$ Polydimethylsiloxane Solid Phase Microextraction (SPME) fiber was used. The SPME fiber was baked prior to use at $250^{\circ} \mathrm{C}$ for 30 minutes following manufacturer's instructions. A $500 \mathrm{~mL}$ Pyrex ${ }^{\circledR}$ Erlenmeyer Flask covered with aluminum foil and parafilm was used as a headspace chamber. The flask was cleaned with technical grade acetone and oven baked at $100^{\circ} \mathrm{C}$ for 1 hour before analysis. Once cooled, one mangosteen leaf sample was placed inside. This was heated to $30^{\circ} \mathrm{C}$ to $40^{\circ} \mathrm{C}$ while the fiber was exposed for 25 minutes. Heating facilitates efficient extraction of the volatile compounds (Silva et al., 2017). After extraction, the fiber was directly injected to the GCMS. Two blank runs were also conducted to ensure the integrity of the yielded data. The first blank involved running the GCMS using the programmed temperature without SPME injection. This was done to make sure that the column used for the testing is clean. The second blank involved the exposure of the SPME fiber to the oven baked flasks which did not contain the leaf samples. All analyses were done in eight replicates.

\section{Chromatographic and Spectroscopic Analysis}

Gas Chromatography coupled to Mass Spectrometry (GC-MS) analysis was performed on Agilent Technologies 7890A GC System and Agilent Technologies 5977A MSD. A HP-5 MS ultra-inlet capillary column (30 m x $250 \mathrm{~mm} \times 0.25 \mathrm{~mm}$ ) was used. The injection temperature was set to $250^{\circ} \mathrm{C}$ and operated on splitless mode. The oven was held at $50^{\circ} \mathrm{C}$ for 5 minutes then programmed at $10^{\circ} \mathrm{C} / 10$ minutes until the final temperature of $200^{\circ} \mathrm{C}$. Helium was used as the carrier gas with constant flow of $1 \mathrm{~mL} /$ min. Detection was performed in Electron Impact (EI) mode. Spectra acquisition was performed in scanning mode (mass range $\mathrm{m} / \mathrm{z}$ 50-550). Chromatograms and spectra were recorded by means of GC/MSD ChemStation Software and MassHunter Workstation with MSD Chemstation DA Software (Agilent Technologies). The identity of the compound was determined by National Institute of Standards and Technology (NIST) Mass Spectral Library 2.0.

\section{Statistical Analysis}

The Mann - Whitney U test for nonparametric analysis was conducted using the software Statistica, on the basis of the com- 
pound peak area. All analyses were done at a $5 \%$ significance level.

\section{Results and Discussion}

The results of the GC-MS analysis on the healthy and infested leaves are presented in Figure 1. Peak identifications were limited to compounds that exhibited match fac- tors greater than 800 , which signifies a high degree of confidence in the identification (Hubschmann, 2015; Stein, 1999). The compounds emitted by infested or healthy mangosteen leaves are summarized in Table 1. The profile of volatile compounds emitted by mangosteen leaves infested with $A$. rigidus was different to the one emitted by healthy leaves. Both quantitative and qualitative differences were found.

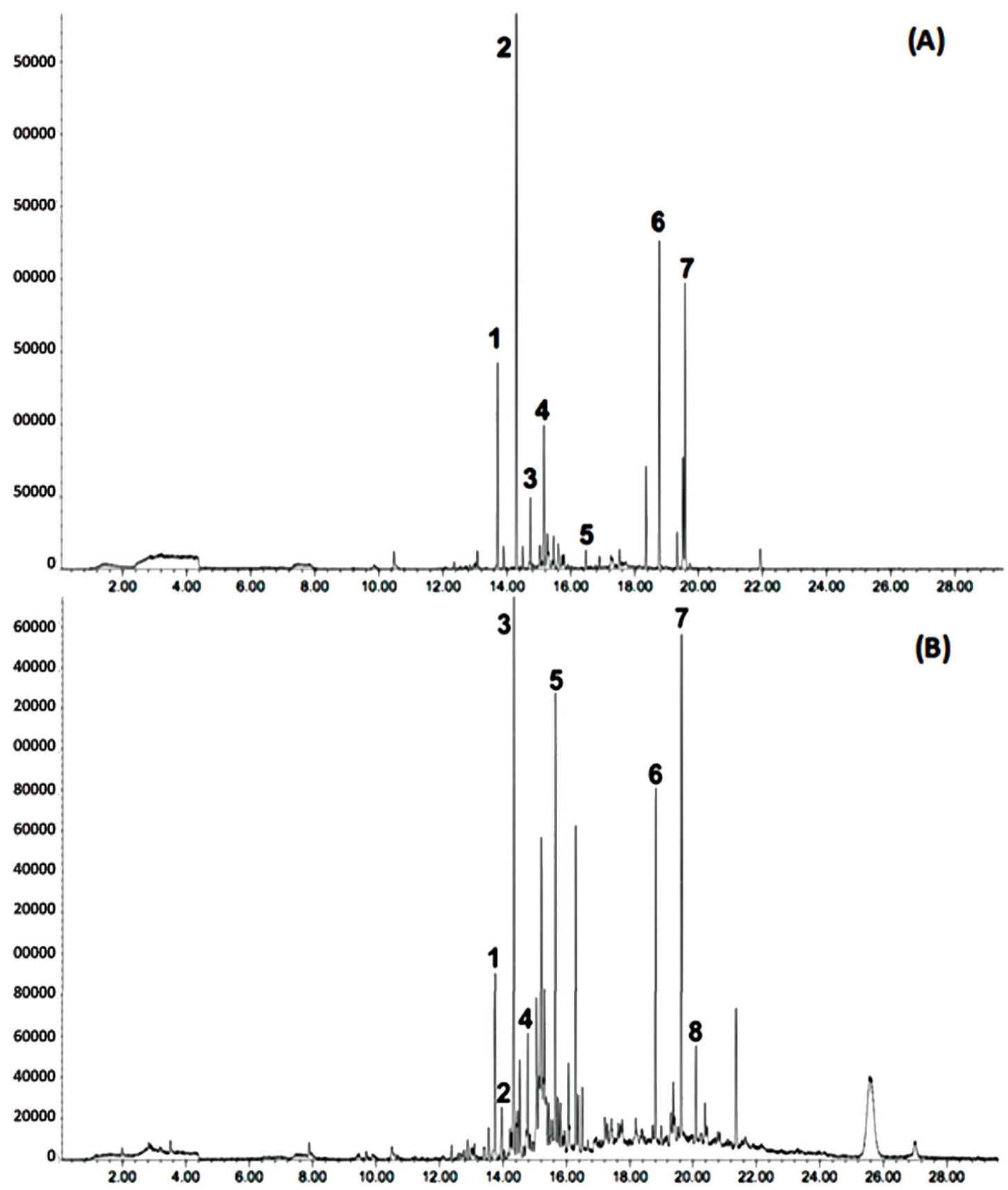

Figure 1. Chromatograms of healthy leaves of Garcinia mangostana (A) and infested leaves by Aspidiotus rigidus (B). 


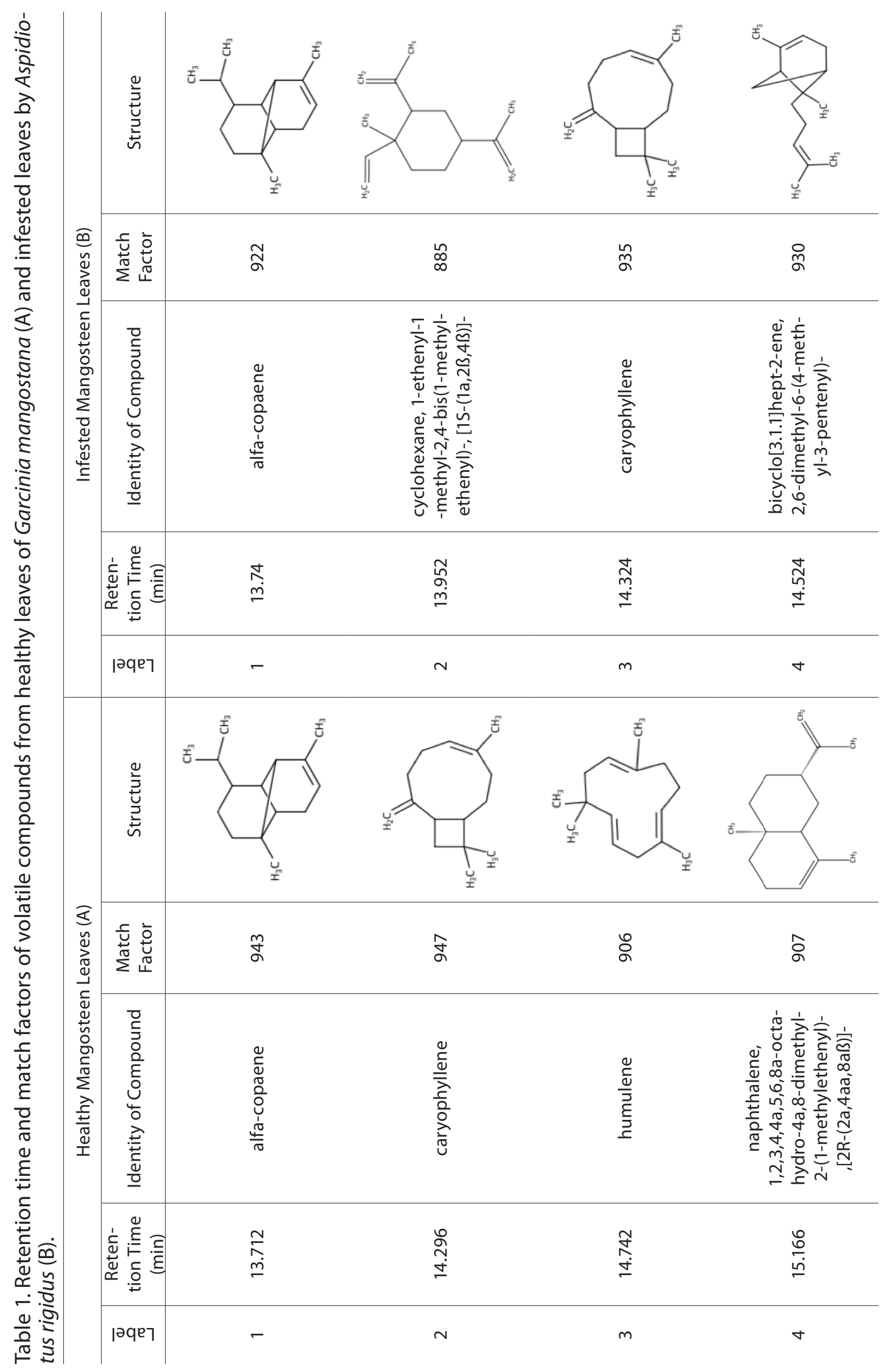



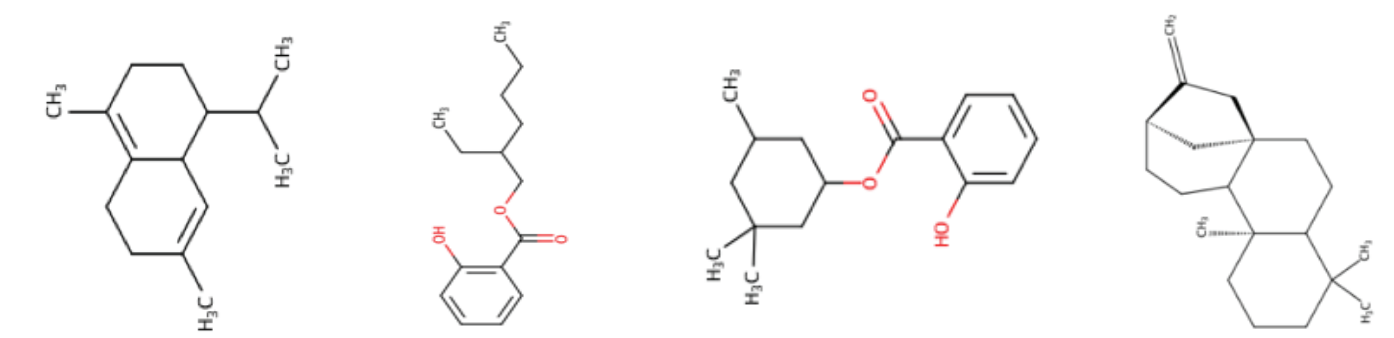

ถัก

$\stackrel{\leftrightarrow}{\infty}$

๙े

\&े
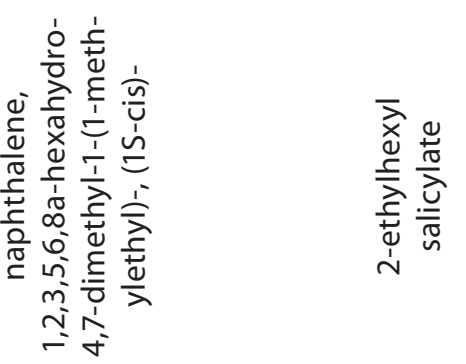

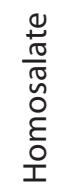

0
$\frac{1}{0}$
1
$\frac{1}{1}$
$\frac{1}{7}$
$\frac{0}{2}$

$\stackrel{+}{\hat{n}}$
Lே

\begin{tabular}{l}
\multirow{D}{0}{} \\
$\infty$ \\
$\infty$
\end{tabular}

m̋
ă

응

เn

0

$\wedge$

$\infty$
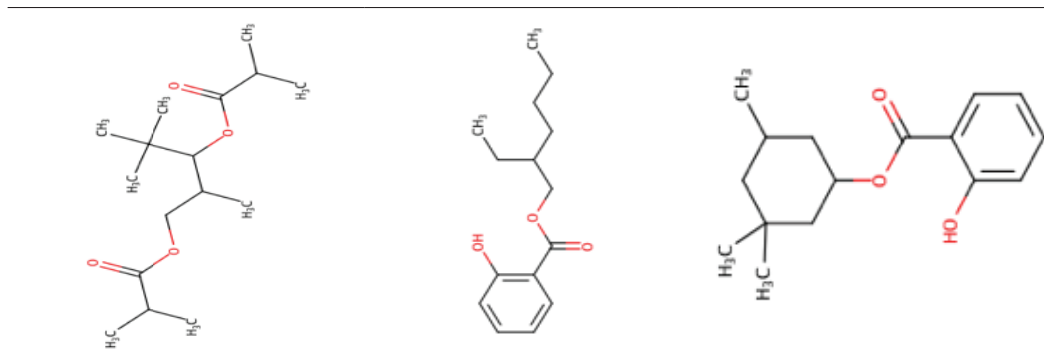

$\stackrel{\sim}{\infty}$

$\underset{\infty}{\infty}$

$\stackrel{\infty}{\alpha}$

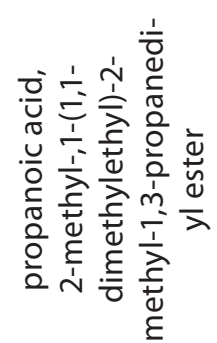

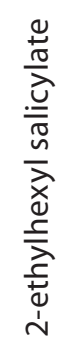

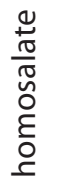

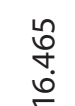

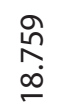

a
ஸे
aे

n

$\bullet$

$\wedge$ 
Caryophyllene, which was a common compound in healthy and infested leaves is a sesquiterpene found in oils produced by plants (Pinho-da-Silva et al., 2012). $\beta$-caryophyllene is one of the most common volatile compounds secreted by plants that has the ability to limit the growth and development of insects infesting plants (Huang et al., 2011). In addition, $\beta$-caryophyllene can attract naturally - occurring parasitoids of the phytophagous insects (Wang et al., 2015).

The volatile compounds cyclohexane, 1-ethenyl-1-methyl-2,4-bis(1-methylethenyl)-, [1S-(1a,2ß,4ß)], bicyclo[3.1.1]hept-2ene, 2,6-dimethyl-6-(4-methyl-3-pentenyl), and kaur-16-ene-were emitted only by mangosteen leaves infested by $A$. rigidus. Notably, kaur-16-ene emission was significantly elevated in infested $v s$ healthy leaves (Mann - Whitney $U$ test, $p$-value $=0.000939$ ). The emission of kaur-16-ene in infested leaves suggests that it is the physiological response of the plant to the infestation of $A$. rigidus which may play a role in the compensation of the plant to the damage.

Kaur-16-ene has been reported to be emitted by coniferous trees in Japan (Matsunaga et al., 2012) but its role in herbivore induced signaling is not known. Kaur-16-ene is recognized to be a precursor to the hormone gibberellic acid (GA) which affects the growth and development of plants (MacMillan 1997). GA helps the plants to compensate the damage caused by certain herbivores (Bari and Jones, 2009). Gibberellins, in general, function as promoters and regulators of growth and development (Otsuka et al., 2004). They also alter plant metabolism and induce physiological responses in plants (e.g. invertase activity and photosynthetic rate) favoring growth under stress (Iqbal et al., 2011). The increased fitness and vitality as a consequence of stress is widespread among plants, and is considered to be a form of adaptive plasticity (Anurag, 1998). Some examples of plants that can exhibit this form of defense adaptation include radish (Anurag, 1999) and tobacco (Kessler and Baldwin, 2004).
In conclusion, the infestation of the scale insect $A$. rigidus on the $G$. mangostana leads to the emission of the terpene kaur-16-ene, which possibly suggests the induction of hormone precursor compounds that will compensate for the damage. Overall, the results presented are expected to contribute to our understanding on the chemical ecological interaction of $A$. rigidus with the host plant and its natural enemies. Future research direction will aim at analyzing the potential of the HIPV kaur-16-ene to attract known parasitoids of $A$. rigidus.

This study was financially supported by the De La Salle University Science Foundation through the University Research Coordination Office (Project Number 48 F S 3TAY14-3TAY15).

\section{Literature Cited}

Anurag, A.A. 1998. Induced responses to herbivory and increased plant performance. Science, 279: 1201-1202.

Anurag, A.A. 1999. Induced response to herbivory in wild raddish: effects on several herbivores and plant fitness. Ecology, 80: 1713-1723.

Bari, R. and Jones, J.D.G. 2009. Role of plant hormones in plant defense responses. Plant Molecular Biology, 69: 473-488.

Bureau of Agricultural Statistics. 2012. Crops Statistics of the Philippines 2007 - 2011 (National and Regional). Quezon City: Department of Agriculture, p. 3.

De Moraes, C.M., Lewis, J.W., Pare, P.W., Alborn, H.T. and Tumlinson, J.H. 1998. Herbivore - infested plants selectively attract parasitoids. Nature, 393: 570-573.

Dicke, M., Sabelis, M.W., Takabayashi, J., Bruin, J. and Posthumus, M.A. 1990. Plant strategies of manipulating predator-prey interactions through allelochemicals: prospects for application in pest control. Journal of Chemical Ecology, 16: 3091-3118.

Dudareva N, Negre F, Nagegowda DA, and Orlova I. 2006. Plant Volatiles: Recent Advances and Future Perspectives. Critical Reviews in Plant Sciences, 25: 417-449.

Huang, M., Sanchez-Moreiras, A.M., Abel, C., Sohrabi, R., Lee, S., Gershenzon, J. and Tholl, D. 2011. The major volatile organic compound emitted from Arabidopsis thaliana flowers, the sesquiterpene $(E)-\beta$-caryophyllene, is a defense against 
a bacterial pathogen. New Phytologist, 193: 9971008.

Hubschmann, H.-J. 2015. Handbook of GC-MS: Fundamentals and Applications, 3rd ed. New Jersey: John Wiley \& Sons.

Iqbal N., Nazar R., Khan M.I.R., Masood A. and Khan N.A. 2011. Role of gibberellins in regulation of source- sink relations under optimal and limiting environmental conditions. Current Science, 100: 998-1007.

Kessler, A. and Baldwin, I.T. 2004. Herbivore-induced plant vaccination. Part I. The orchestration of plant defenses in nature and their fitness consequences in the wild tobacco species Nicotania attenuata. The Plant Journal, 38: 639-649.

MacMillan, J. 1997. Biosynthesis of the gibberellin plant hormones. Natural Product Reports, 14: 221-223.

Matsunaga, S.N., Chatani, S., Nakatsuka, S., Kusumoto, D., Kubota, K., Utsumi, Y., Enoki, T., Tani, A. and Hiura, T. 2012. Determination and potential importance of diterpene (kaur-16-ene) emitted from dominant coniferous trees in Japan. Chemosphere, 87: 886-893.

Miller, D.R., Miller, G.L., Hodges, G.S. and Davidson, J.A. 2005. Introduced scale insects (Hemiptera: Coccoidea) of the United States and their impacts on U.S. agriculture. Proceedings - Entomological Society of Washington, 107: 123-158.

Otsuka M., Kenmoku H., Ogawa M., Okada K., Mitsuhashi W., Sassa T., Kamiya Y., Toyomasu T. and Yamaguchi S. 2004. Emission of ent-kaurene, a diterpenoid hydrocarbon precursor for gibberellins, into the headspace from plants. Plant and Cell Physiology, 45: 1129-1138.

Pinho-da-Silva, L., Mendes-Maia, P.V., do Nascimento Garcia Teofilo, T.M., Barbosa, R., Ceccatto, V.M., Coelho-de-Souza, A.N., Cruz, J.S. and Leal-Cardoso, J.H. 2012. trans-caryophyllene, a natural sesquiterpene, causes tracheal smooth muscle relaxation through blockade of voltage-dependent $\mathrm{Ca}^{2+}$ channels. Molecules, 17: 11965-11977.

Schuman, M.C., Barthel, K. and Baldwin, I.T. 2012. Herbivory - induced volatiles function as defenses increasing fitness of the native plant Nicotania attenuata in nature. eLife, 1:e00007.

Shrivastava G., Rogers, M., Wszelaki, A., Panthee, D.R. and Chen, F. 2010. Plant volatiles-based insect pest management in organic farming. Critical Reviews in Plant Sciences, 29:123-133.

Silva, E.A.S., Saboia, G., Jorge, N.C., Hoffmann, C., dos Santos Isaias, R.M., Soares, G.L.G. and Zini, C.A. 2017. Development of a HS-SPME-GC/MS protocol assisted by chemometric tools to study herbivore-induced volatiles in Myrcia splendens. Talanta, 175: 9-20.

Stein S.E. 1999. An Integrated Method for Spectrum Extraction and Compound Identification from Gas Chromatography/Mass Spectrometry Data. Journal of the American Society for Mass Spectrometry, 10: 770-781.

Wang, Q., Xin, Z., Li, J., Hu, L., Lou, Y. and Lu, J. 2015. $(E)$ - $\beta$-caryophyllene functions as a host location signal for the rice white-backed planthopper Sogatella furcifera. Physiological and Molecular Plant Pathology, 91: 106-112.

Watson G.W., Adalla C.B., Shepard B.M. and Carner G.R. 2015. Aspidiotus rigidus Reyne (Hemiptera: Diaspididae): a devastating pest of coconut in the Philippines. Agricultural and Forest Entomology, 17: 1-8.

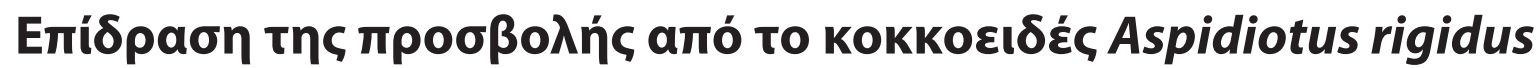

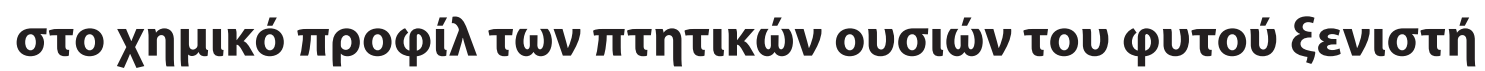 Garcinia mangostana
}

\author{
M.A.A. Tavera, J.C.A. Lago, V.K.D. Magalong, G.A.V. Vidamo, J.S.R. Carandang VI, \\ D.M. Amalin kaı J.I.B. Janairo
}

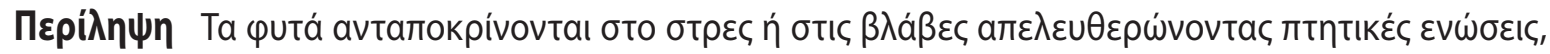

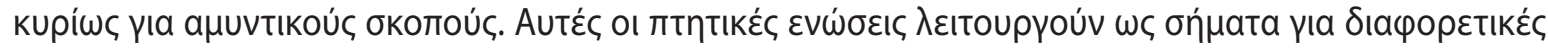

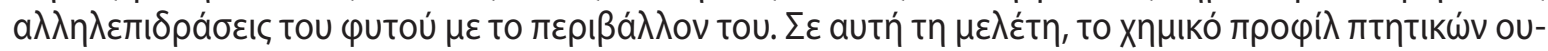

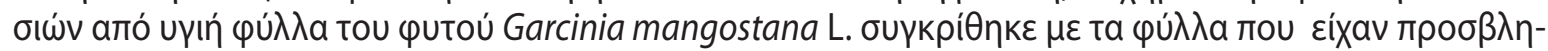

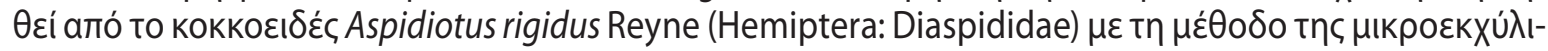

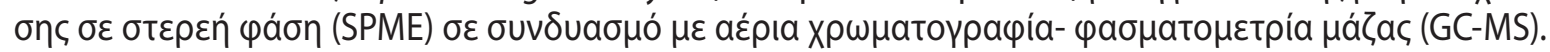




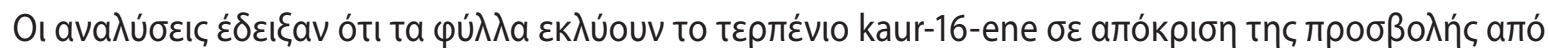

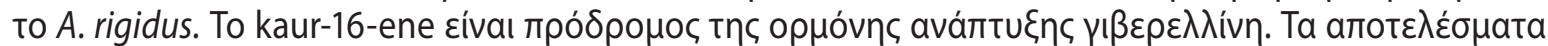

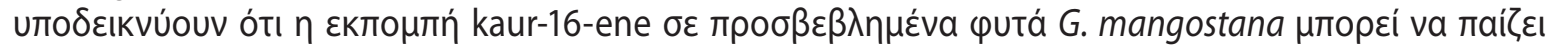

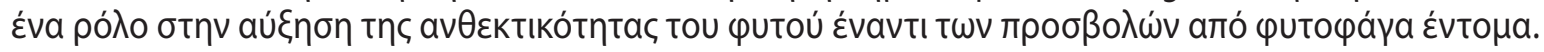

Hellenic Plant Protection Journal 11: 1-8, 2018 